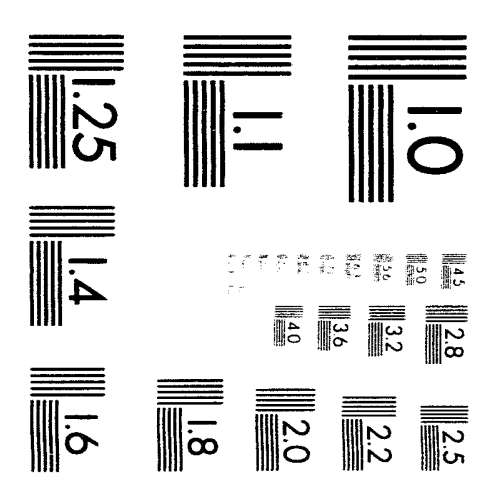



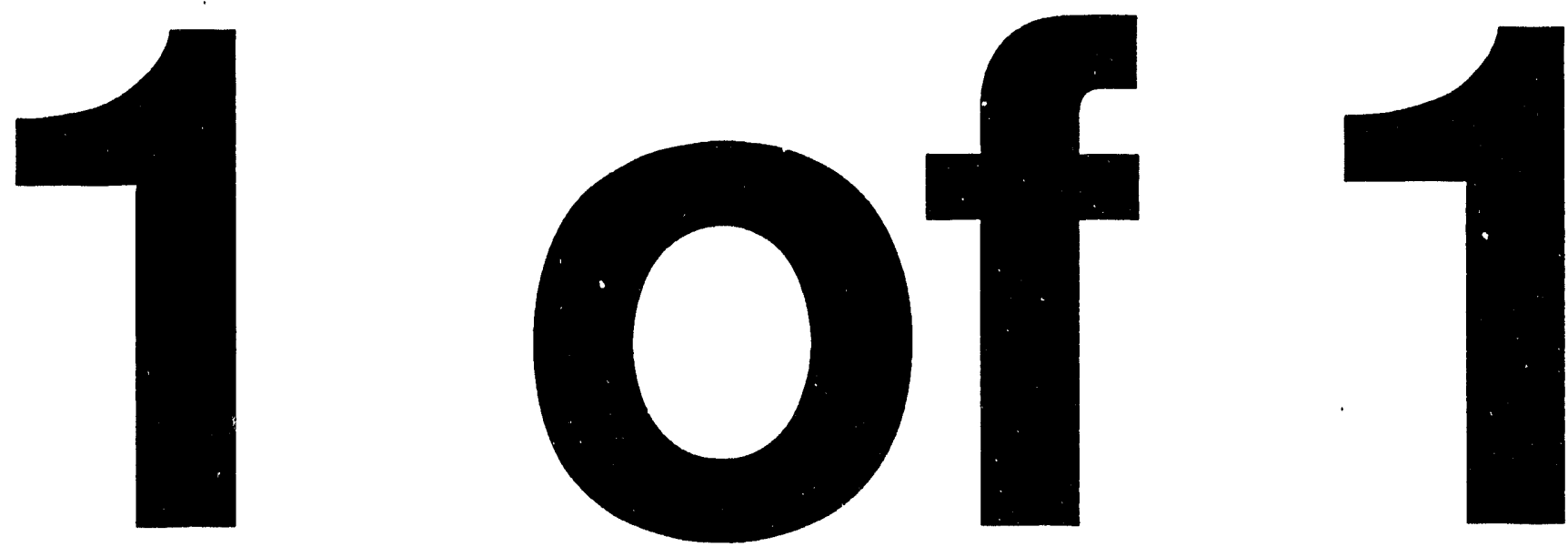


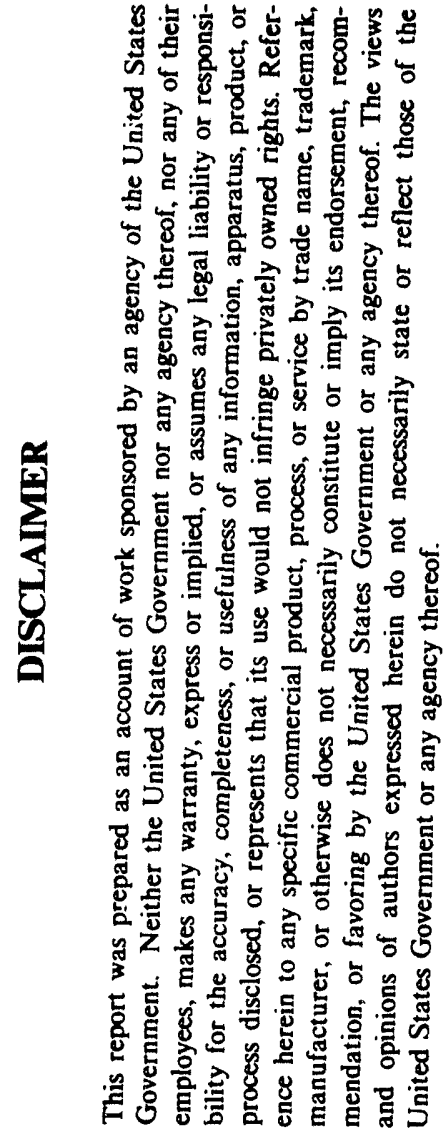

Author(s): Carol L. Talcott, James L. Anderson,

R. V. Carlson, D. O. Coffin, C. R. Walthers, D. Hamerdinger,

K. Binning, R. D. Trujillo, J. S. Moya

Tritium Science and Technology Group

Materials Science and Technology Division

T. Hayashi, K. Okuno, T. Yamanishi

Japan Atomic Energy Research Institute

Submitted to:

IEEE/NPSS 15th Symposium on Fusion Engineering

October 11 thru 15, 1993, Hyannis, Massachusetts

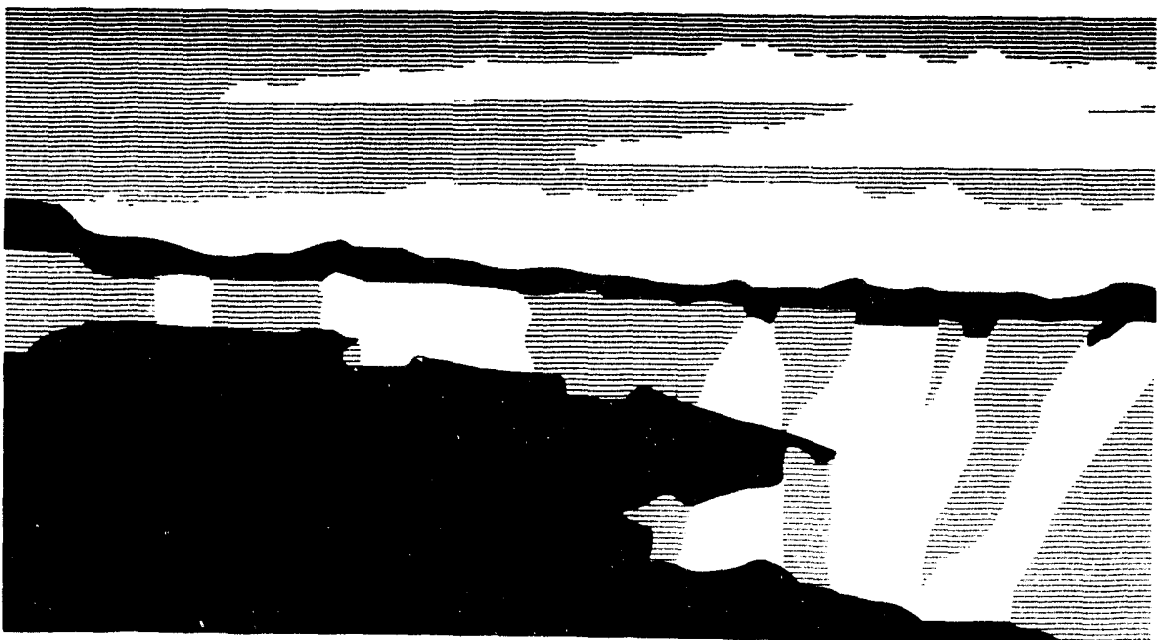

Los Alamos National Laboratory, an affirmative action/equal opportunity employer, is operated by the University of California for the U.S. Department of Energy under contract W-7405-ENG-36. By acceptance of this article, the publisher recognizes that the U.S. Government retains a nonexclusive, royalty-free license to publish or reproduce the published torm of this contribution, or to allow others to do so, for U.S. Government purposes. The Los Alamos National Laboratory requests that the publisher identity this article as work pertormed under the auspices of the U.S. Department of Energy. 


\title{
Three Tritium Systems 'Test Assembly (TSTA) Off-Loop Experiments
}

\author{
C. L. Talcott, J. L. Anderson, \\ R. V. Carlson, D. O. Coffin, C. R. Walthers, \\ D. Hamerdinger, K. Binnirg, R.D. Trujillo, J. S. Moya \\ L.os Alamos National Laboratory \\ 'Tritium Science and Technology Group \\ Mail Stop C-348 \\ Los Alamos, New Mexico 87545 \\ T. Hayashi, K. Okuno, T. Yamanishi \\ Japan Atomic Energy Research Institute
}

\section{EXPERIMENT \# 1 \\ Effect of Tritium on Viton-A, Buna-n and EDPM Elastomers at 1, 40 and 400 Torr During Valve Cycling}

ABSTRRACT

'Two O-ring valve seals cach of Viton- $A$, Buna-N, and EDPM were exposed 10 1, 40, or 400 torr of uritum while being eycled open and ciosed approximalely 11,500 times in 192 clays. EDPM is the least susceptible to damage from the tritium. Both Buna-N and Viton-A showed deterioration following the first cycling at 400 iorr.

\section{INTRODUC'TION}

This work was initiated to establish the possibility of using a soft elastomer in I'TIER (International Thermonuclear Experimental Reactor) applications. Used in this application, the sealing material is anticipgted to be in tritium at pressures in the range of $1 \times 10^{-3}$ (orr for many years. Accelerated tests over a range of higher pressures were used in this study in order to extrapolate the results to the low pressure range.

\section{EXPIRIMENTAL}

Eighteen elastomer ()-ring valve seals are studied (6) determine tritium compatibility under high use conditions for 192 days. Three sets of six test valves, latbeled $\triangle-F$ in ligh. 1, are used. Fach valve is opened and closed in tritium 1100 times during 11 days then lested for leakage across the valve seall. This procedure is repeated 11 times. During eyeling, set 1 contatined trifimm all 1 form while sels 2 and 3 conlain litium al 4) forr and for) lorr, respectively. Valves not shown in the figure isolate the different valve sels during the eyeling and leatikns.

1

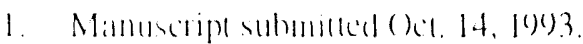

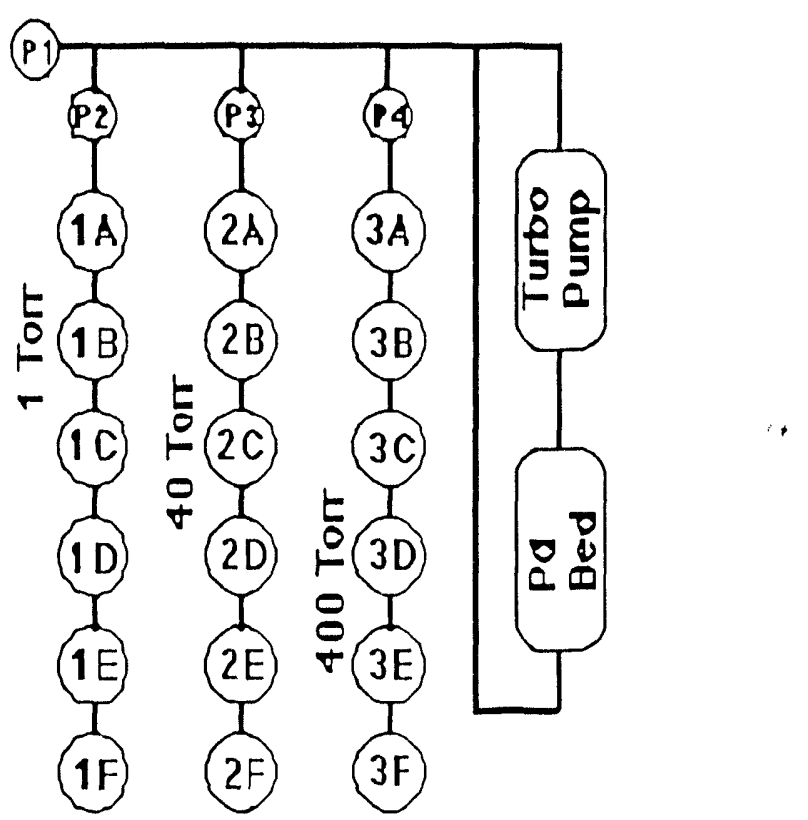

P1 ()-2 Torr Pressure Transducer

P2 ()-10 Torr Pressure Transducer

P3 0-100 Torr Fressure lransducer

P4 0-1000 Torr Pressure Transducer

1^-3I Test Valves

Pd Bed Palladium Bed used to store, supply and pump tritium.

ligg. I Simplified diagram of test valve arrangement for the elawomer test

All volumes arsociated with the test valves are calihlated so that presure shanges can be used to calculate leith ralles. A palladium hed is used as the seneree of tritium during the prexess of londing tritium inte the est value lines by heating or conling the hed ats necessally lo establish the desired tritium overpessure. Thibiun transter (n) and from the experimem is done with

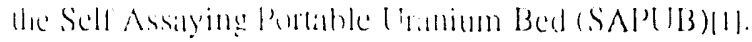

milially, lle latk rate of the est baldes is deter-

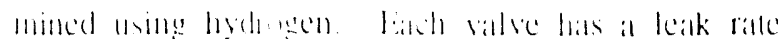


under $1 \times 10^{-5} \mathrm{~S} T \mathrm{~T}-\mathrm{ce} / \mathrm{sec}$ which is the specified limit. Tritium is added to the system in aliquots for a final leak check and to replace the hydrogen adsorbed on the system surfaces. After the valves are cycled for 11 days in the respective pressures, the tritium pressure is equalized in each valve set at approximately 140 torr. Leak rates are determined by closing all valves and evacuating the calibrated manifold beyond the valves in Fig. 1. Once the manifold is isolated from the vacuum, the pressure change in the manifold volume is used to calculate the leak rate of a test valve. Once this measurement is made, the test valve is opened and the pressure is noted to establish an accurate back-pressure behind the valve. The volume is again evacuated and the subsequent pressure rise is used to determine the leak rate through the next test valve. This procedure is used for the remaining valves. As a result, some of the valves at the end of the test cycle experience a pressure of 140 torr for up (0) 30 hours, allhough not during the cycling operations. Elastoner placement, shown in Table 1, was staggered in each line to avoid its position effecting the interpretation of the results.

Table 1

Elastomer placement in each line.

\begin{tabular}{|c|c|c|c|c|c|c|}
\hline \multirow{2}{*}{$\frac{\text { Pressure }}{\text { T'orr }}$} & \multicolumn{5}{|c|}{ Valve Positions } & \multirow[b]{2}{*}{ "F" } \\
\hline & "A" & "B" & “"(") & "D" & "I:" & \\
\hline 1 & V & B & E & V & B & $\mathrm{E}$ \\
\hline 40) & B & E: & V & B & $E$ & V \\
\hline 400 & I: & V & $B$ & $1:$ & V & B \\
\hline $\begin{array}{l}\mathrm{V}=\text { Viton- } \\
\mathrm{B}=\text { Buna-n } \\
\mathrm{E}=\mathrm{EIDPM}\end{array}$ & & & & & & \\
\hline
\end{tabular}

\section{Torr Series}

Buna-N Viton-A EDPM
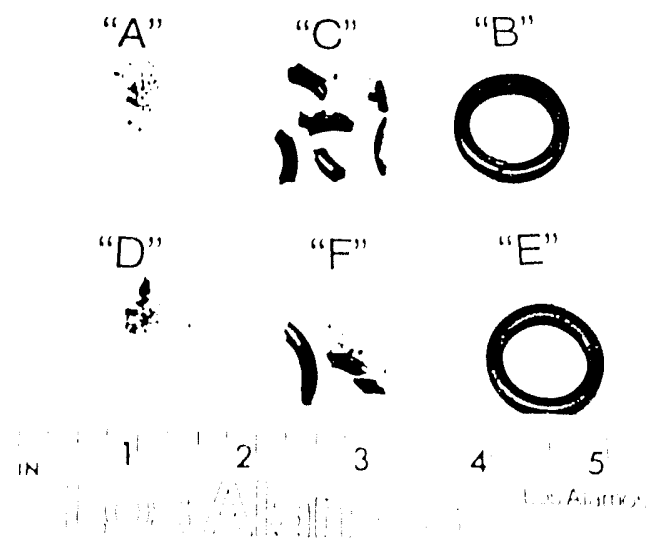

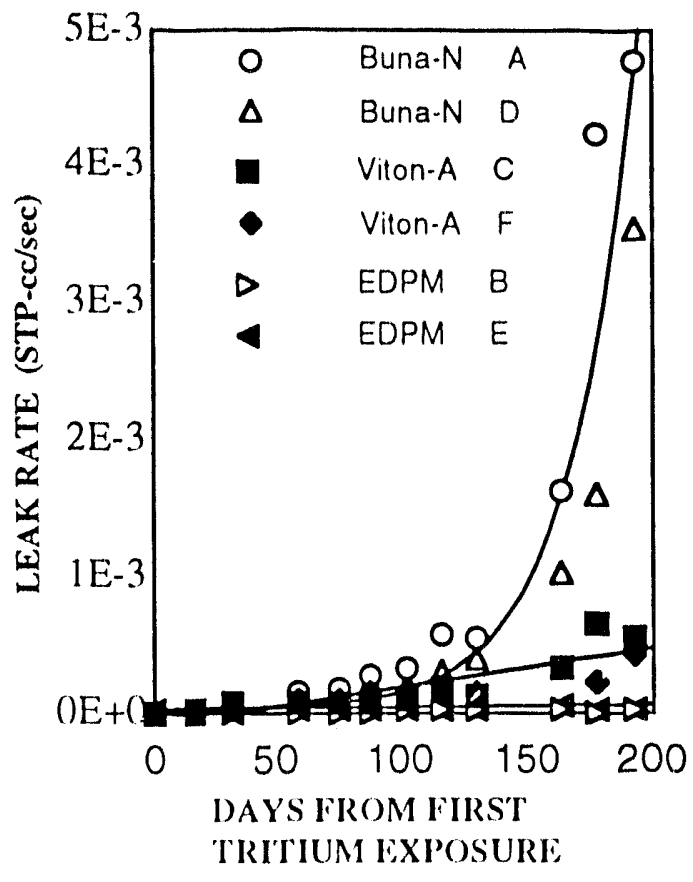

Fig. 3. Leak rate vs. days of tritium exposure during 40 Torr series.

\section{RESULTS}

Figure 2 shows a photograph of the three different materials after the test. Buna-n failed most dramatically. The elastomer is dull, hard, brittle and flattened. No large piece of the elastomer could be removed intact. Viton-A is intermediate in hehavior. A few pieces could be extracted from the valve. The surface of this material is also that and dull. EDPM shows the best compatibility with tritium. Although the surface of the elastomer shows dullness, it can te removed intact.

Figure 3 shows leak rates from the 40 torr set of valves ats a function of time after initial exposure. This time is somewhall longer than the time during which the material was in actual contact with tritium. Buna-n clearly responds perorly (o) tritium, the Viton-A slightly better, and the LIDPM is best. As leak rates became large, valves at the end of the series lost significant back-pressure. All back pressures were conected it) 140 torr ro comprinsate for this pressure loss.

Figure 4 shows logg leak tate as a function of time after initial exposure for Bunti-n at the three different pressures. Rapid fialure ocours after a delay time that depends on the witum pressure. This delay time is ploted in lögure 5 an a function of trifium pressure. Extrapolation of this figure on 1 x $10^{-3}$ torr suggests that Bunta-n would list up (1) 1 years. The Viton-A would

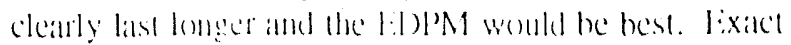
estimate of lifetimes have nent yed been oblained from dhis werk lor the's matlerials

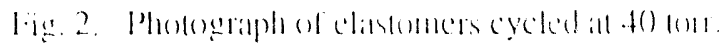




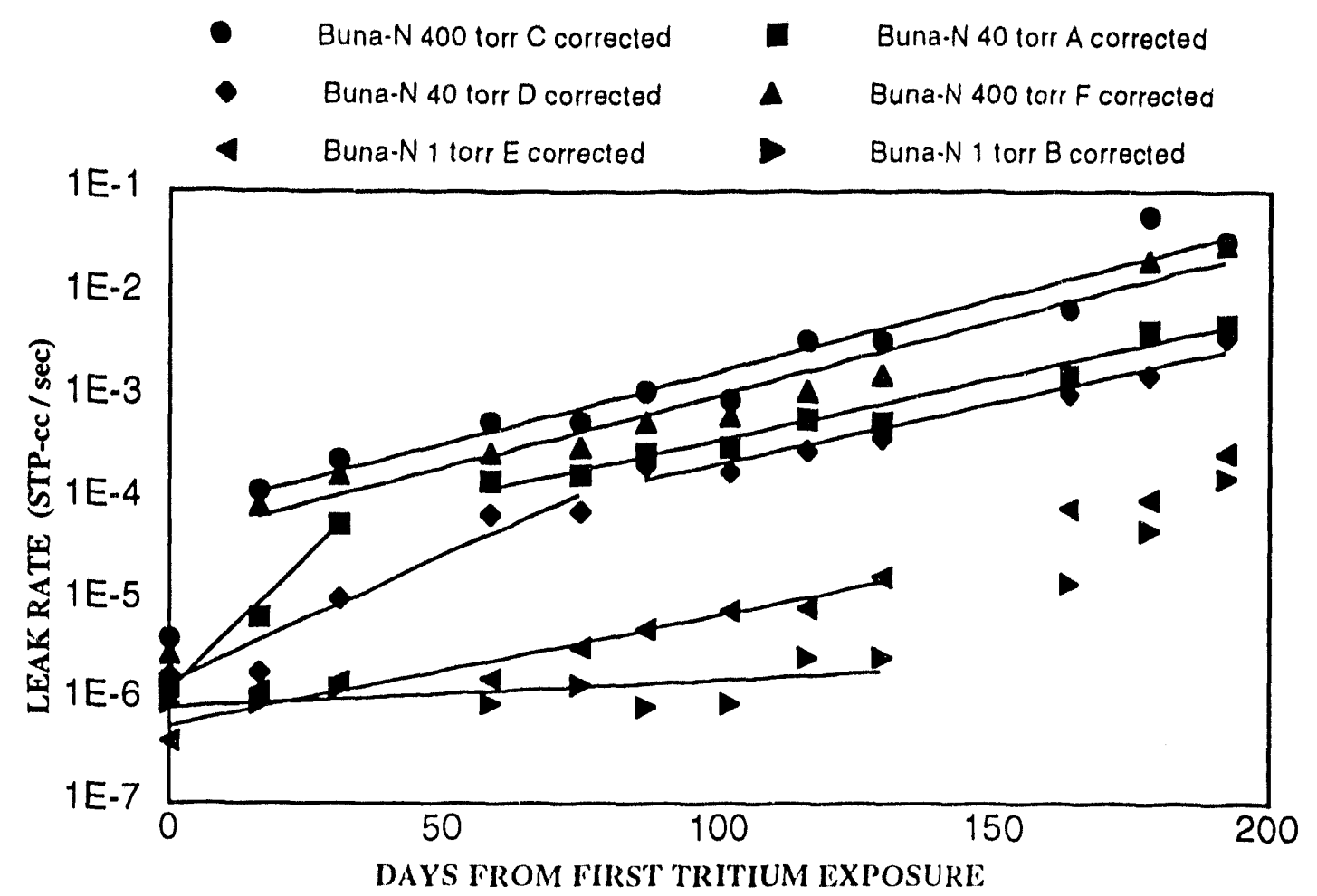

Fig. 4. Leak rate vs.days from first tritium exposure for Buna-n.

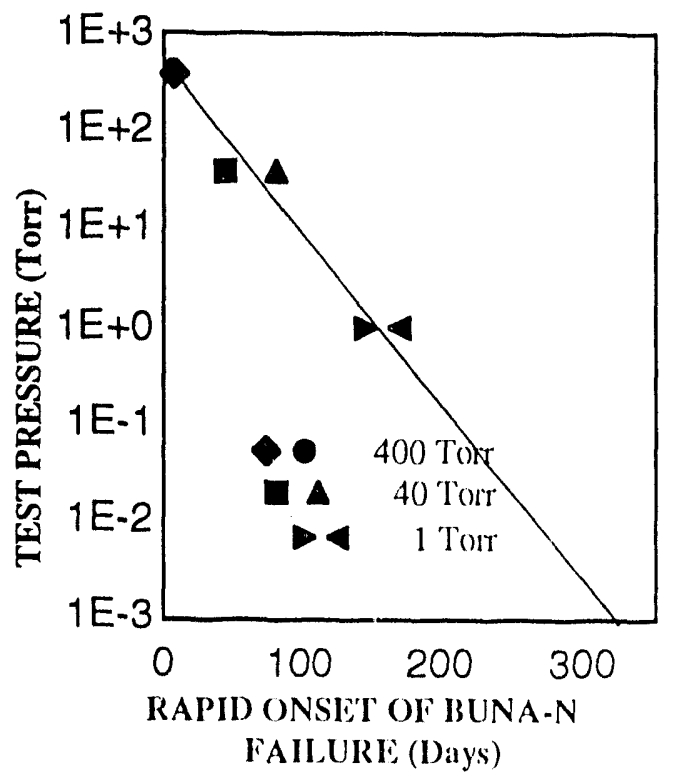

Fig. 5. Extrapolated service life an low pressures.

\section{CONCLUSIONS}

Buna-n is estimated (o) last up to 1 year all $100^{-3}$ torr be. fore failing rapidly. Quantitative lifetimes have non been oblained for Viton-A or IEDPM. Howerer, there is no question that of the three materials, EDPM sustains the least danage from tritium exposure. A comparison between this work and that of Wylie et. al.(2) shows that frequent cycling decreases the lifetime of an elastomer seal when in contact with tritium.

\section{EXPERIMENT \#2}

Tests of a Portable Water Removal Unit Designed to Reduce Stack Emissions

\section{ABSTRACT}

Using commercially available materials, the Tritium Systems Test Assembly (TSTA) designed and huill a Portable Watter Removal (PWR) Unit to reduce tritium oxide emisions during glovetox breaches. The PWR removes 9y.9\% of all tritium and saves between 0.7 and 3.5 curies of tritium oxide from being stacked during each of the five lests.

\section{INTRODUCTION}

Al'ST'A in in often necessary to remove a glovebox window (o) portom hatintainance. In order to keep

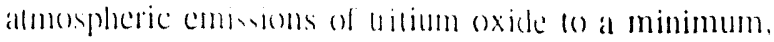
J'SlA designed a device w reduce tritium emissions 10 we slate. The MIR is poritioned between a glovebox 
and the stack (see ligg. (1) during window removal operations. A more versatile and sophisticated system for tritium work is in use at Sandia Livermore|3]

\section{EXPERIMENTAL.}

The system shown in Figure 6 is placed between a glovebox and the stack. The molecular sieve is contained between two barriers. The top barrier is a screen similar to that used on a screen door and keeps the sieve in the holder if the unit is lipped. The bottom frit is $5 \mu \mathrm{m}, 40 \mu \mathrm{m}$ or $100 \mu \mathrm{m}$ pore size fritted steel and keeps tritiated dust from entering the blower and ducts. Because of the large flow resistance, this frit is a major factor in restricting airflow. Any number of straight segments filled with sieve can be added. Temperature of the sieve is monitored as well as air llow. Gas is sampled for tritium concentration before and after the sieve. This gas is relurned to the PWR.

Disposal of the sieve has not created a problem be cause the tritiated sieve is poured into solict-waste disposal barrels. These barrels contain tritiated plumbing and other large parts so that the sieve eccupies the void spaces after the barrel is "filled" (hus creating no additional waste barrels.

When a glovebox breach is planned, a moisture source is placed in the glovebox the night before the PWR is used. This exchanges HTO adsorbed on the glovebox walls with $\mathrm{H}_{2} \mathrm{O}$.

The PWR is connected to the glovebox through a glove port while a window or second glove-port opening supplics room air.

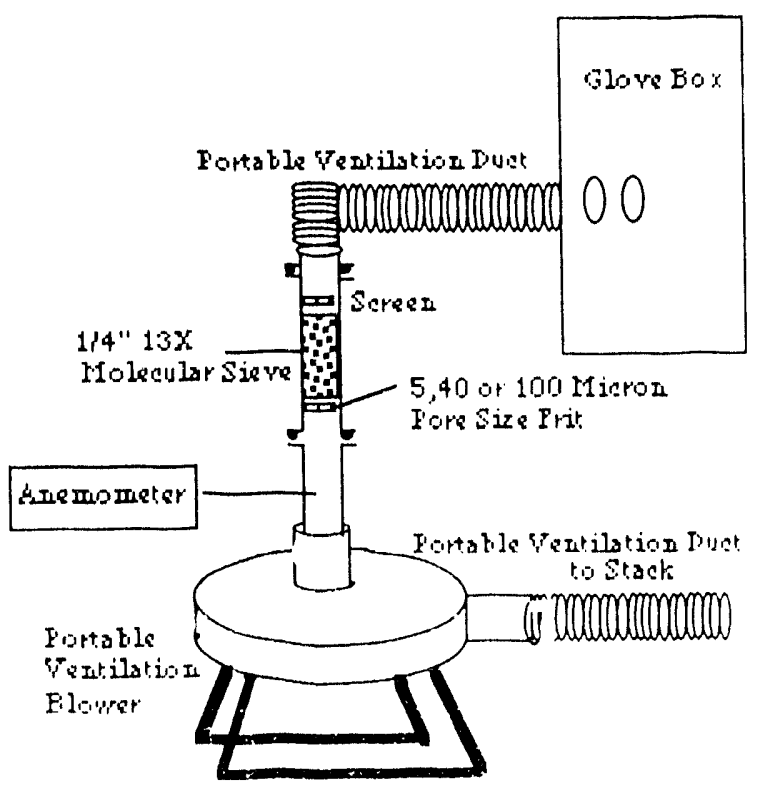

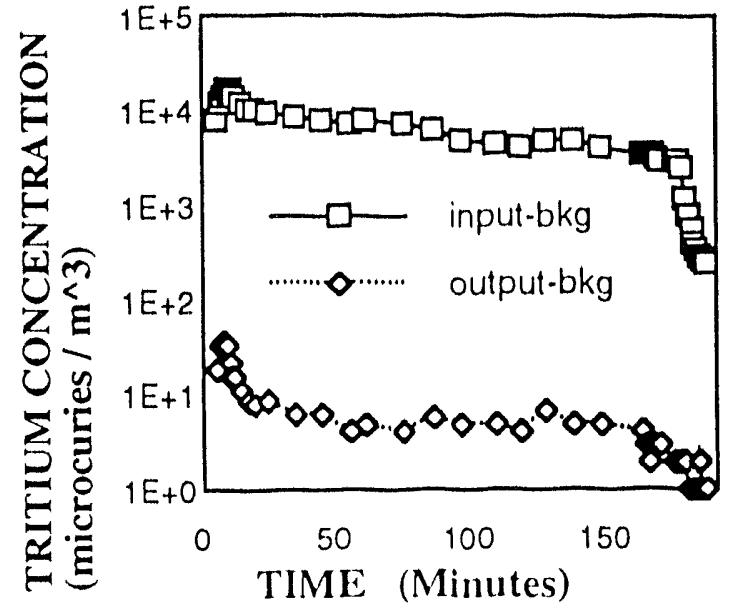

Fig. 7. Tritium input and output of the PWR. One Curie was collected in run 3 .

ing supplies room air. Tritium concentration at the inlet and coullet of the PWR during a typical run is shown in

lig. 7. One curie of tritium was collected in the sieve during this run.

The following information is recorded: tritium concentration entering the PWR, tritium concentration leaving the PWR, flow rate of the gas stream in the PWR, total quantity of gas through the PWR, and time of the reading. Temperature of the sieve container is used as a guide to indicate when the sieve may be near saturation. Breakthrough was not observed during these lests. Table 2 shows that the PWR is very effective in reducing tritium emission. Additional studies are needed to determine the optimum gas flow rate and the effectiveness of calalytic-palladium coated sieve to convert $T_{2}(0) T_{2}$ () within the PWR[4].

Table 2

Results of I'WR tests

\begin{tabular}{|c|c|c|c|}
\hline Rum & Poresize & Elficiency" & Tritium Trapned \\
\hline & micron & nercenl & curic \\
\hline 1 & 5 & $(y)+2$ & $1^{2}$ \\
\hline 2 & 5 & ()(9.9) & 1.05 \\
\hline 3 & 5 & ()! !) & 1.18 \\
\hline$t$ & 5 & (1)! !) & 3.40 \\
\hline 5 & $l(x)$ & (1)! (9) & 0.72 \\
\hline
\end{tabular}

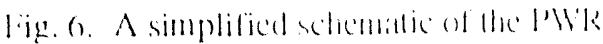




\section{ACKNOWLEDGEMENTS}

Thanks are given to all TSTA personnel for their helpful suggestions and participation in PWR lests.

\section{EXPIRIMENT \#3 \\ Performance of Hydrogen /Oxygen Recombination Catalysts in the Presence of Tritium and $\mathrm{SF}_{6}$}

\section{ABSTRACT}

$A$ series of tests are done to determine whether the presence of $\mathrm{SF}_{6}$ changes the ability of palladium and platinum to catalyze the $\mathrm{T}_{2}-\mathrm{O}_{2}$ reaction 10 form $\mathrm{l}_{2}$ (). $\mathrm{No}$ deterioration of the catalytic activity is observed.

\section{INTROIUUCTION}

Tokamak Fusion 'Test Reactor (TIFTR) requires information about the effect of $\mathrm{SF}_{6}$, an electrical insulat tor, on the catalytic hehavior of $P$ t and $P d$ in a $T_{2}$ environment. This information is necessary for the aceident analysis in the Safety Analysis Repont for TTFR. This study is done using an apparatus supplied to TS'l' $\mathrm{A}$ by TTITR.

\section{FXPLEIMENTAI}

lïgure 8 shows a simplified schematic of the $\mathrm{Sl}_{6}$ system. The gases $\left(\mathrm{SF}_{6}\right.$, dry air and $\mathrm{T}_{2}$ ) ate mixed, preheated, and passed through the catalyst hed. Id on

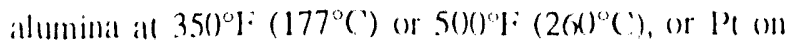
alumina al $950^{\circ} \mathrm{F}\left(510^{\circ} \mathrm{C}\right)$ are used as callalysts. All $\mathrm{l}_{2} \mathrm{O}$ resulting from the reaction is collected in a water bubbler. Unreacted $\mathrm{T}_{2}$ passes through the bubbler and is converted $10 \mathrm{~T}_{2} \mathrm{O}$ in an oxidized-copper furnace at $7.50^{\circ} \%\left(399^{\circ} \mathrm{C}\right)$. The $\mathrm{T}_{2} \mathrm{O}$ formed in the (un furnace is collected in a second bubbler. Remaining gas is refurned to the mixing volume. An ion chamber with a small circulating pump is altached to the mixing volume and used to monitor tritium concentration in the gals. Gas circulation is continued for 30 minutes after the tritium level has dropped below $9 \%$ of the original value. Hydrogen is then flushed durough the system to remove any adsorbed tritium. An additional step is required when the palladium catalyst is used. Because the alumina substrate tends to absorb walce, the Pd callalyst is heated to $750^{\circ} \mathrm{F}$. To drive any tritiated water into the bubbler.

Prior to every run, dry air is passed through the system while only the Copper bed is heated. (Onee the (u is fully oxidized, the catalyst is tested at each of the cemperalures using a mixlure of dry air and trilium. This test is followed by a similar study using a mixture of dry air, tritium and $\mathrm{SF}_{6}$. Each gas sample contained. approximately one curie of tritium, and alxout $3.5\left(\mathrm{i} / \mathrm{m}^{3}\right.$ in the total gas sample. All experiments are donce using a single sample of each calalyst.

The bubblers are filled with a meatsured amount of ethylene glycol or water. After gas is circulated for 101.5 minutes, liquid samples are removed for scintillation analysis. Dilution is based on weight rather than volume measurement in order to reduce croror.

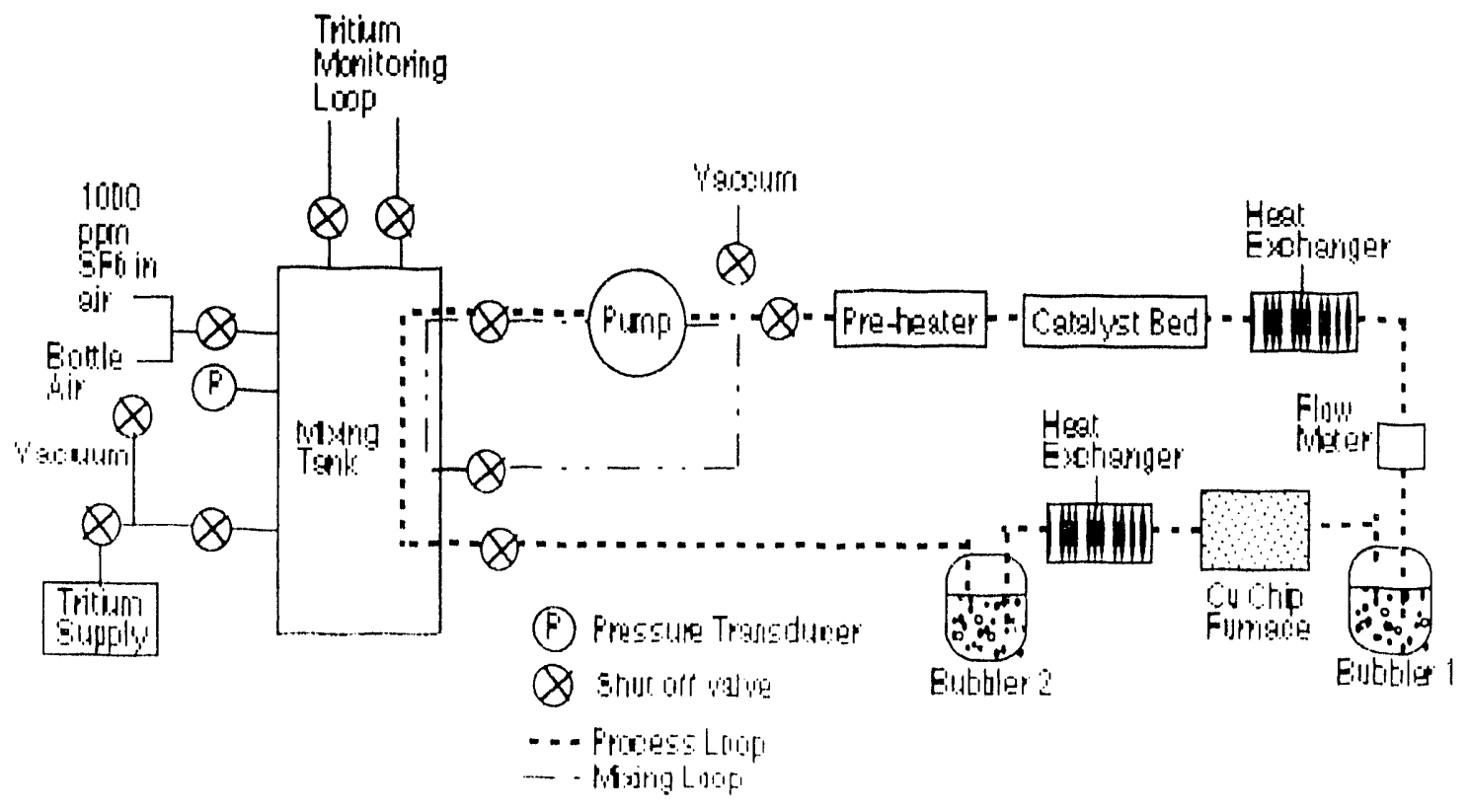

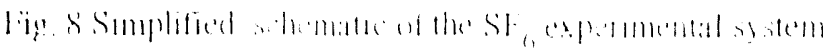




\section{RESULTS}

Effectiveness of the catalyst is deternined by di. viding the tritium concentration in the first bubbler by the sum of the tritium concentrations in the first and second bubblers. The results are tabulated in Table 3. The two runs on $\mathrm{Pd}$ at $350^{\circ} \mathrm{F}$ show adequate repeatahility for the supplied system. pears to have no effectontre catalytic atwivity of these catalysts.

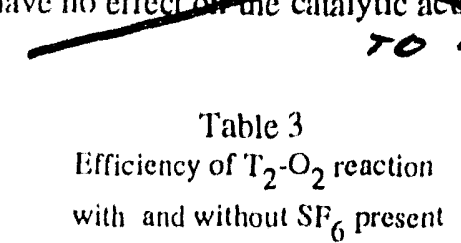

13) M. Mintz, Lawrence Livernore National L aboratory system description in Nuclear Waste News, Aug, 1993 More information available from M. Mintz at (510)-422-8394

[4] Persomal Communication A. Nobile

\begin{tabular}{|c|c|c|c|}
\hline \multirow[t]{2}{*}{ Material } & \multirow{2}{*}{$\frac{\text { Temperature }}{F}$} & \multicolumn{2}{|c|}{$\%$ Efficiency } \\
\hline & & $I_{2}-$ & $\mathrm{I}_{2}+\mathrm{SE}_{6}(\mathrm{p} p \mathrm{pu})$ \\
\hline Palladium & 350 & $97.8,97.2$ & $99.0(35 \mathrm{pmm})$ \\
\hline Palladium & 500 & 96.9 & $96.5(3.5 \mathrm{ppm})$ \\
\hline Platinum & 350 & $98.7,98.5$ & * \\
\hline Platinum & 500 & 98.1 & * \\
\hline Platinum & 950 & 98.5 & $\begin{array}{l}98.2(3.5 \mathrm{pmm}) \\
07.5(100 \mathrm{pmml})\end{array}$ \\
\hline
\end{tabular}

* Runs were determined to have less priority by TTFTR and were preempted.

\section{CONCLUSIONS}

The presence of $\mathrm{SF}_{6}$ appears to have no effect on the catalytic activity of these catalysts.

\section{ACKNOWLEDGEMENTS}

This work is supported by the U.S. Department of Energy, Office of Fusion Energy

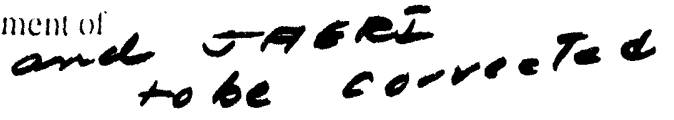

The writer participated in all three of these experiments after the concepts and original construction werc complete. I thank all of the people who made this prossible. I also thank my husband, Fidmund Storms, who patiently helped me edit this manuscript to produce it camnera-readly format.

\section{RLFERENCLS.}

III ('R. Wilthers, E.M. Jenkins, I os Alames Nit.

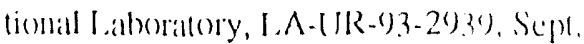
19)3. Presented at this conference

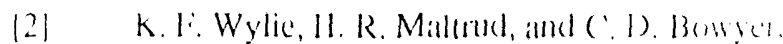

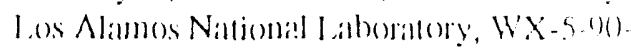

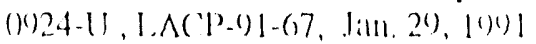



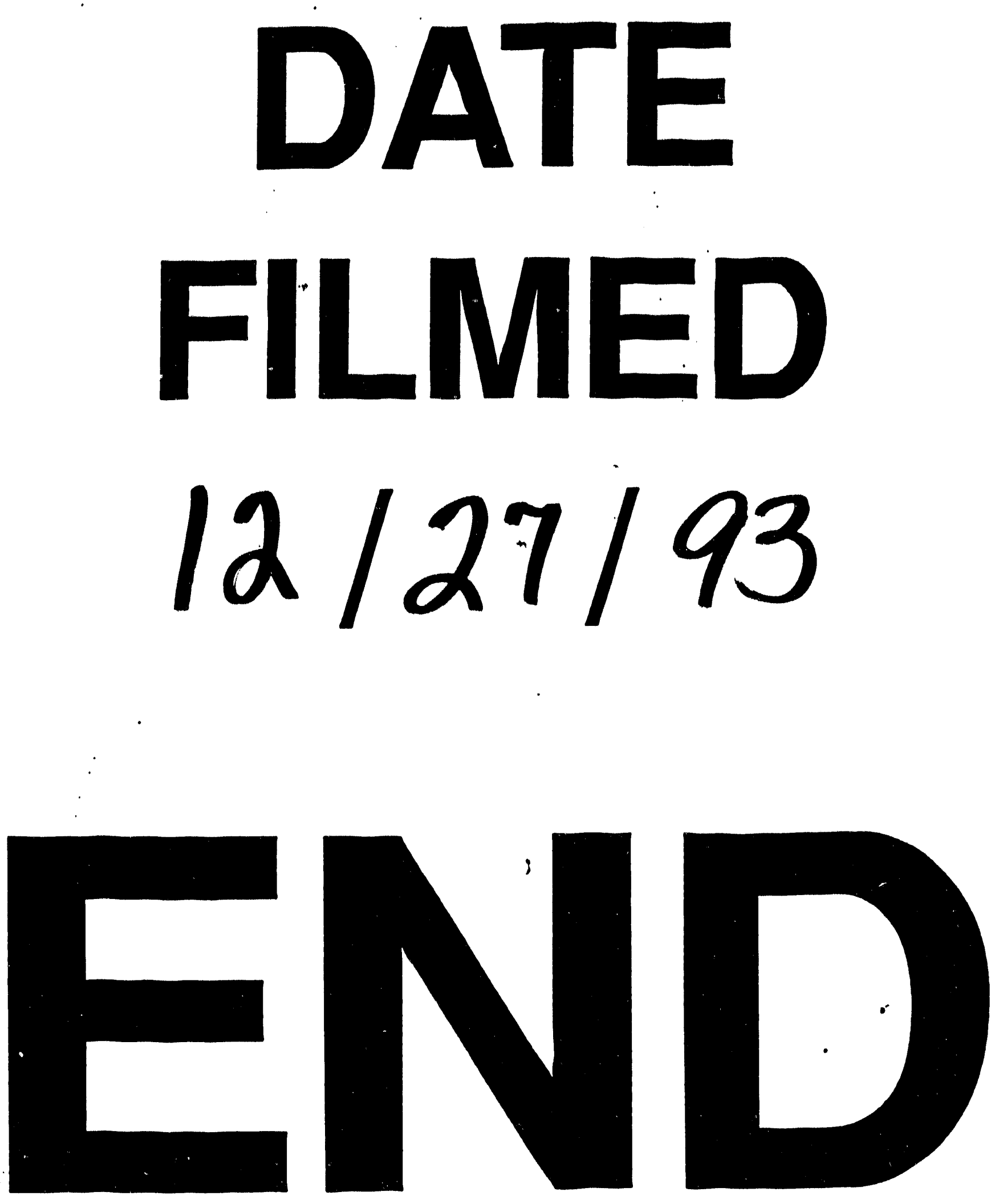
| 